\section{Delivering clinical case management for frequent callers to ambulance services}

\author{
Jason Scott
}

Ambulance services in England are playing an increasing role in the provision of care. Their role has changed from one of picking up patients in the community and dropping them off at an emergency department (ED) to more advanced care models. These now include the provision of clinical advice over the telephone (hear and treat), the treatment of patients on-scene (see and treat) and the more traditional conveyance to the ED. ${ }^{1}$ These changes have been occurring during a prolonged period of increased demand on all areas of emergency care, including a $47 \%$ rise in ED attendance over 15 years. $^{2}$ Further, it is known that frequent users of healthcare use a disproportionate amount of resources. ${ }^{3}$

\section{CLINICAL CASE MANAGEMENT FOR FREQUENT CALLERS}

The paper by Edwards et $a l^{4}$ provides one of the first examples of delivering interventions for frequent callers to an English ambulance service and is one of few publications on the topic internationally. ${ }^{5}$ There are three notable findings that are discussed in this commentary:

1. Frequent callers were found to be heterogeneous with 95 (86\%) falling within more than category

2. Ten different types of interventions were used, although 90 (82\%) patients received five or fewer

3. The interventions as a whole showed a reduction in median calls from five per month preintervention to zero per month postintervention.

These findings are of importance for both research and practice. First, the heterogeneous profile of patients within this study suggests that, similar to frequent users of the $\mathrm{ED}^{6}{ }^{6}$ there are potential

Correspondence to Dr Jason Scott, Institute of Health and Society, Newcastle University, BaddileyClark Building, Richardson Road, Newcastle upon Tyne NE2 4AX, UK; jason.scott@ncl.ac.uk subgroups of frequent callers. However, there is still much research to be done before they can be fully identified due to the paucity of research within ambulance services. ${ }^{5}$

Second, that there were 10 intervention types demonstrates the complexity of care associated with this group of patients who may require the support of various health and social care services. While this potentially serves as a note of caution, complexity should be sought to be understood rather than avoided. Indeed, this could serve as an opportunity for ambulance services that have been recognised as being able to coordinate and lead the integration of health and social care services, ${ }^{7}$ which coincides with perspectives on transforming the healthcare system for the delivery of more integrated care. ${ }^{8}$

Third, the reduction in calls is a promising indication that, from an ambulance service perspective, providing interventions can reduce service usage and possibly free up resources that are needed elsewhere. Nevertheless, caution should be noted when interpreting the impact of clinical case management. As Edwards et al have acknowledged, the lack of a control group means that reductions in usage cannot be fully attributed to the interventions. Roland and $\mathrm{Abel}^{9}$ have recently cautioned against ignoring regression to the mean; given that patients were registered for up to 24.5 months at the maximum end of the range, it is entirely possible that this contributed to the result. Further research would provide an insight into the extent regression to the mean has impacted on the study outcome.

\section{WHAT DOES QUALITY MEAN TO FREQUENT CALLERS?}

There is a risk that frequent callers, once identified by ambulance services, are simply passed to another service ${ }^{10}$ so that budgetary rather than patient needs are met. As such, it must be remembered that many patients will be frequently calling ambulance services because they are not receiving adequate care, as opposed to calling for vexatious reasons. ${ }^{6}$ Qualitative research is needed to identify outcomes that are of importance to frequent callers and understand the mechanisms by which interventions for frequent callers work.

Competing interests None.

Provenance and peer review Commissioned; internally peer reviewed.

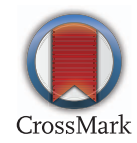

To cite Scott J. Emerg Med J 2015;32:342.

Received 23 September 2014

Revised 6 October 2014

Accepted 7 October 2014

Published Online First 29 October 2014

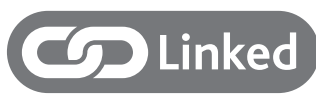

- http://dx.doi.org/10.1136/emermed-2013-203496

Emerg Med J 2015;32:342.

doi:10.1136/emermed-2014-204354

\section{REFERENCES}

1 Department of Health. Taking healthcare to the patient: transforming NHS Ambulance Services. London: Department of Health, 2005.

2 National Audit Office. Emergency admissions to hospital: managing the demand. London: The Stationery Office, 2013.

3 Pines JM, Asplin BR, Kaji AH, et al. Frequent users of emergency department services: gaps in knowledge and a proposed research Agenda. Acad Emerg Med 2011;18:e64-9.

4 Edwards MJ, Bassett G, Sinden L, et al. Frequent callers to the ambulance service: patient profiling and impact of case management on patient utilisation of the ambulance service. Emerg Med J 2015;32:393-7.

5 Scott J, Strickland AP, Warner K, et al. Frequent callers to and users of emergency medical systems: a systematic review. Emerg Med I 2014; 31:684-91.

6 LaCalle E, Rabin E. Frequent users of emergency departments: the myths, the data, and the policy implications. Ann Emerg Med 2010;56:42-8.

7 House of Commons Health Committee. Urgent and Emergency Services: Second Report of Session 201314. London: The Stationery Office, 2013.

8 Naylor C, Imison C, Addicott R, et al. Transforming our health care system. London: The King's Fund, 2013.

9 Roland M, Abel G. Reducing emergency admissions: are we on the right track? BMJ 2012;345:e6017.

10 Mason SM. Frequent attendance at the emergency department is a symptom but not a disease. Emerg Med J 2014;31:524-25. 